\title{
Mortalidade por "septicemia dos peixes tropicais" em tilápias criadas em consorciação com suínos
}

[Edwardsiella septicemia mortality in tilapia-integrated with pig in fish farming]

\author{
M.C.S. Muratori ${ }^{1}$, N.E. Martins ${ }^{2}$, M.T.D. Peixoto ${ }^{2}$, A.L. Oliveira $^{2}$, L.P. Ribeiro ${ }^{2}$, \\ A.P.R. Costa ${ }^{1}$, M.C.C. Silva ${ }^{3}$, R.C. Leite ${ }^{2}$. \\ Centro de Ciências Agrárias da UFPI \\ 64.049-550 - Teresina, PI \\ ${ }^{2}$ Escola de Veterinária, UFMG, Belo Horizonte, MG \\ ${ }^{3}$ Fundação Ezequiel Dias, Belo Horizonte, MG
}

Recebido para publicação em 21 de março de 2000

Recebido para publicação, após modificações, em 8 de novembro de 2001

E-mail chrismuratori@bol.com.br

\section{RESUMO}

Com o objetivo de estudar a variação sazonal da septicemia dos peixes tropicais provocada por Edwardsiella tarda foram observadas 50 tilápias (Oreochromis sp.) no verão, 45 no outono, 55 no inverno e 105 na primavera. Os peixes doentes apresentavam opacidade de córnea, dificuldade respiratória, nado desordenado, nódulos nas brânquias e lesões hemorrágicas na pele e nadadeiras. Após três dias de observação as tilápias morriam naturalmente. Nas necrópsias foi encontrado ascite com distensão da cavidade celomática e lesões hemorrágicas e necróticas no fígado, baço e rins. No interior do tubo digestivo observou-se enterite hemorrágica. Isolou-se Edwardsiella tarda a partir de provas positivas para $\mathrm{H}_{2} \mathrm{~S}$, lisina, indol, motilidade e glicose com gás. Os índices de mortalidade foram: na primavera $69,9 \%$, no inverno $63,6 \%$, no verão $48,0 \%$ e no outono $40,0 \%$.

Palavras-chave: Peixe, tilápia, consórcio suíno-piscicultura, Edwardsiella tarda, septicemia dos peixes tropicais

\begin{abstract}
A rural property was observed for one year to obtain seasonal observations of Edwardsiella septicemia in tilapias (Oreochromis sp.) from an integrated fish farm (using pig excrements as food). Fifty tilapias on summer, forty-five on autumn, fifty-five on winter and one hundred and five on spring were collected and evaluated microbiologically for the presence of Edwardsiella tarda. Samples of the external surface (skin, gills and fin), intestines and muscle were analyzed. Fishes were transported alive to the laboratory, and maintained for five days for observation. The external signs observed were opacity of cornea, respiratory difficulty, disordered swimming, nodules on gills, hemorrhagic lesions under the skin and fins and incoordination of the posterior part of the body. In general, after three days of observation, the tilapias died. At necropsy, ascites with the distension of the celomatic cavity, hemorrhagic and necrotic lesions in the liver, spleen and kidneys were found. Hemorrhagic enteritis was observed in the gut tube. Edwardsiella tarda isolated presented the following biochemical profile: negative urea, sucrose, phenylalanine desaminase and malonate utilization, and positive indole, methyl red, $\mathrm{H}_{2} \mathrm{~S}$, motility, glucose with gas production and lysine decarboxylase. The mortality rates were $69.9 \%$ on spring, $63.6 \%$
\end{abstract}




\section{Muratori et al.}

on winter, $48.0 \%$ on summer and $40.0 \%$ on autumn, highest rates occurring on spring and winter $(P<0,05)$.

Keywords: Fish, tilapia, Edwardsiella septicemia, Edwardsiella tarda, fish-pig integration

\section{INTRODUÇÃO}

Edwardsiella tarda tem sido considerada como bactéria emergente para enfermidades transmitidas através de alimentos (Doyle, 1989). São bastonetes Gram negativos curtos (1 $\mu \mathrm{m}$ de diâmetro e com comprimento de 2 a $3 \mu \mathrm{m}$ ), pertencentes à família Enterobacteriaceae, anaeróbios facultativos, mesófilos (crescem em temperatura entre 20 e $35^{\circ} \mathrm{C}$ segundo Holt et al., 1994). Ocorrem freqüentemente em intestinos de répteis, peixes e anfíbios e ambientes limnológicos, podendo também ocorrer em intestinos de mamíferos (Holt et al., 1994).

E. tarda é patogênica para peixes, podendo causar lesões na pele e vísceras, principalmente no verão, quando o ambiente hídrico na região tropical apresenta temperaturas médias de $30^{\circ} \mathrm{C}$ (Noga, 1996; Pavanelli et al., 1998), e no começo de outono (Post, 1983). Quando o habitat apresenta elevados teores de matéria orgânica, podem ocorrer lesões mesmo em temperaturas ambientes entre 10 a $18^{\circ} \mathrm{C}(\mathrm{Noga}$, 1996). Condições de estresse também podem desencadear sintomas de septicemia dos peixes tropicais (Noga, 1996; Pavanelli et al., 1998).

Piscicultores utilizam, com freqüência, fezes de animais domésticos para fertilizar as águas dos viveiros para produção de algas e para alimentação dos peixes. Esse procedimento pode causar aumento da matéria orgânica, o que favorece o aumento de bactérias e a diminuição da concentração de oxigênio, podendo causar enfermidades nos peixes (Perdomo, 1996).

A enfermidade causada pela E. tarda em peixes é conhecida como "septicemia dos peixes tropicais", apresentando sintomas tais como: lesões hemorrágicas cutâneas que podem evoluir para abcessos com tecido necrótico e odor desagradável, despigmentação cutânea, nódulos nas brânquias (Pastor, 1981; Noga, 1996; Pavanelli et al., 1998), hiperplasia epitelial, necrose de linha lateral e opacidade de córnea (Noga, 1996). Na forma septicêmica ocorrem ascite, distensão da cavidade celomática, exoftalmia, prolapso anal e nódulos brancos no fígado, rins e baço (Pavanelli et al., 1998). Apresenta mortalidade entre 5\% e 30\% (Pastor, 1981; Pavanelli et al., 1998) e morbilidade entre 5 e 70\% (Pastor, 1981).

Apesar de ser considerada como bactéria de animais de sangue frio, pode acometer mamíferos, inclusive o homem, e causar principalmente gastroenterite e até meningite (Pastor, 1981; Noga, 1996; Nettles \& Sexton, 1997; Pavanelli et al., 1998), infecção renal (Pastor, 1981) e abscesso no fígado e na pele (Noga, 1996). Nettles \& Sexton (1997) relatam um caso de endocardite causado por E. tarda em paciente aidético.

Bernoth (1991) classifica E. tarda como patógenos potenciais transmitidas ao homem por peixes de água doce, que ocorrem naturalmente em ambientes aquáticos. A contaminação humana ocorre por via oral (Noga, 1996), sendo recomendando cuidados durante manipulação e preparo de peixes (Bernoth, 1991).

Edwardsiella tarda é considerada pela Comissão Técnica Nacional de Biossegurança - CTNBio (Brasil, 1997) como agente etiológico pertencente à classe de risco 2 (risco individual moderado e risco limitado para a comunidade), da qual fazem parte patógenos que causam doença ao homem ou aos animais, mas que não constituem sério risco para quem os manipulam em condições seguras. As normas se aplicam em contenção de microrganismos não modificados geneticamente, assegurando a biossegurança das pessoas, dos animais e do meio ambiente. 
Dessa forma, o objetivo deste trabalho foi o de avaliar a variação sazonal da septicemia provocada por Edwardsiella tarda em tilápias (Oreochromis sp.) consorciadas com suínos em propriedade rural.

\section{MATERIAL E MÉTODOS}

Para observação sazonal da ocorrência de Edwardsiella tarda em tilápias (Oreochromis sp.) consorciadas com suínos, durante um ano fez-se o acompanhamento de uma propriedade rural cuja atividade está consolidada por 10 anos. Foram amostradas 50 tilápias no verão, 45 no outono, 55 no inverno e 105 na primavera que apresentavam alterações macroscópicas na superfície externa.

Os peixes foram criados em um viveiro, sobre o qual havia duas pocilgas suspensas, de modo que os dejetos dos suínos caiam diretamente na água.

As tilápias capturadas diretamente do viveiro por meio de tarrafa eram acondicionadas em sacos plásticos contendo água do viveiro acrescida de oxigênio. Elas eram transportadas vivas para o laboratório, setor de piscicultura da Escola de Veterinária da Universidade Federal de Minas Gerais, onde permaneciam em observação por cinco dias em caixas d'água com capacidade para 1000 litros, com fluxo de renovação constante de 160 litros/hora de água potável, que passavam por dois filtros para remoção de cloro e partículas sólidas, proporcionando 5,6 trocas por hora.

Após cinco dias de observação os peixes que apresentaram morte espontânea eram prontamente necropsiados. Zaragatoas foram passados diretamente nas lesões e o material por elas absorvido era imediatamente inoculado em caldo BHI e incubado a $35^{\circ} \mathrm{C}$ por 24 horas. Após esse período as zaragatoas eram semeadas em agar SS e Hectoen por $24 \mathrm{~h} / 35^{\circ} \mathrm{C}$. As colônias transparentes e produtoras de $\mathrm{H}_{2} \mathrm{~S}$ eram incubadas em agar Pessoa-Silva para prova bioquímica. Foram consideradas Edwardsiella tarda as bactérias que apresentaram as seguintes provas positivas: $\mathrm{H}_{2} \mathrm{~S}$, lisina, indol, motilidade e glicose com gás. As cepas positivas foram encaminhadas à Fundação Oswaldo Cruz (FIOCRUZ) para confirmação do isolamento.

Foram também feitos acompanhamentos físico-químicos da água do viveiro em que eram criadas as tilápias. De manhã, no momento da coleta, verificava-se sua temperatura por meio de termômetro de máxima e mínima.

Para o acompanhamento das condições ambientais do viveiro, foram recolhidas cinco amostras de água por estação do ano em frascos de vidro âmbar para análises de $\mathrm{pH}$, nitrito $\left(\mathrm{NO}_{2}\right)$, nitrato $\left(\mathrm{NO}_{3}\right)$ e demanda química de oxigênio (DQO). Para pesquisa da demanda bioquímica de oxigênio (DBO), as amostras de água foram recolhidas em frasco transparente, preenchendo-o completamente até a tampa, de forma cuidadosa e lenta para evitar a formação de bolhas. As amostras para amônia foram coletadas em frascos âmbar que continham $1 \mathrm{ml}$ de ácido sulfúrico. Para oxigênio dissolvido, as amostras foram coletadas em frasco transparente com cuidado para evitar formação de bolhas de ar. A seguir o oxigênio foi fixado por meio de alíquota de $1 \mathrm{ml}$ de solução de sulfato manganoso e após agitação manual do frasco foi acrescentado $1 \mathrm{ml}$ de solução de iodeto de potássio com nova agitação manual. Após precipitação das partículas sólidas, foi acrescentado ácido sulfúrico concentrado com nova agitação manual até dissolução do precipitado. A seguir as amostras foram acondicionadas e encaminhadas para o Laboratório de Análise de Águas da Escola de Engenharia da UFMG.

Para análise de oxigênio dissolvido (OD) foi utilizado o método de Winkler modificado, para DBO o método azida modificado, para DQO a técnica titulométrica do bicromato de potássio (fluxo fechado) e para $\mathrm{NO}_{3}, \mathrm{NO}_{2}$, fósforo e amônia foram utilizados métodos colorimétricos do salicilato, sulfanilamida e vanado molibidato. As análises de $\mathrm{pH}$ foram feitas por potenciometria. Todas as análises químicas foram feitas em triplicata, utilizando teste em branco para confirmação. Utilizou-se o teste do qui-quadrado para análises estatísticas. 


\section{Muratori et al.}

\section{RESULTADOS E DISCUSSÃO}

Durante o período de observação, os peixes doentes apresentavam opacidade de córnea, dificuldade respiratória, nado desordenado, nódulos nas brânquias e lesões hemorrágicas na pele e nas nadadeiras, o que está de acordo com a descrição da septicemia dos peixes tropicais pelos autores consultados (Pastor, 1981; Noga, 1996; Pavanelli et al., 1998). Em geral, as tilápias que apresentavam lesões típicas da forma septicêmica (Pavanelli et al., 1998) morriam após três dias de observação.

Nos peixes necropsiados foram encontradas lesões hemorrágicas e necróticas no fígado, baço e rins e, ainda, ascite com distensão da cavidade celomática. No interior do tubo digestivo observou-se enterite hemorrágica. O fígado apresentava aspecto friável com coloração escura. Estes sinais são compatíveis com a forma septicêmica da doença (Pavanelli et al., 1998).

Pelos exames bacteriológicos foi possível isolar Edwardsiella tarda do material colhido nas lesões. O isolamento do agente e as lesões macroscópicas típicas encontradas caracterizaram o diagnóstico de septicemia dos peixes tropicais, tendo sido possível determinar as duas formas de apresentação da doença, cutânea e septicêmica (Pavanelli et al., 1998).

Os animais que apresentavam lesões dérmicas e branquiais discretas conseguiram sobreviver após permanecerem, em média, por uma semana em água limpa. Após esse tempo, eles reconstituíam as áreas lesadas, com recuperação do epitélio da epiderme e nadadeiras em aproximadamente uma semana. A morbilidade foi dentro do esperado, entre 30,5\% e 60,0\% (Tab. 1), semelhante à mencionada na literatura (Pastor, 1981).

No inverno e na primavera ocorreram os maiores índices de mortalidade $\left(\chi^{2}=14,6 ; \mathrm{P}<0,05\right)$, acima dos descritos na literatura (Pastor, 1981; Pavanelli et al., 1998).

Tabela 1. Avaliação sazonal da mortalidade por edwardsielose em tilápias criados em viveiros com dejetos de suínos.

\begin{tabular}{lccccc}
\hline Estação do ano & Amostra & Doentes & \% de morbilidade & Mortos & \% de mortalidade \\
\hline Verão & 50 & 26 & 52,0 & 24 & 48,8 \\
Outono & 45 & 27 & 60,0 & 18 & 40,0 \\
Inverno & 55 & 20 & 36,4 & 35 & 63,6 \\
Primavera & 105 & 32 & 30,5 & 73 & 69,5 \\
\hline
\end{tabular}

$\left(\chi^{2}=14,6 ; \mathrm{P}<0,05\right)$.

A patogenicidade da Edwardsiella tarda parece ter sido influenciada pela temperatura da água do viveiro, aspecto já descrito por outros autores (Post, 1983; Noga, 1996; Pavanelli et al., 1998). A média anual de temperatura do viveiro foi de $24,3^{\circ} \mathrm{C}$, observando-se a menor no outono e a maior no verão (Tab. 2 ). Essas medidas de temperatura, obtidas pela manhã, são compatíveis com o desenvolvimento de bactérias mesófilas. Durante o dia, em função do aquecimento pelo sol, a temperatura da água aumenta, favorecendo o desenvolvimento da Edwardsiella tarda (Post, 1983; Holt, et al., 1994; Noga, 1996; Pavanelli et al., 1998).

Tabela 2. Variação média da sazonalidade das características físico-químicas da água do viveiro de tilápias que receberam dejetos de suínos

\begin{tabular}{lccccccccccc}
\hline Estação & Temp. & $\mathrm{pH}$ & Nitrato & Nitrito & DBO & DBQ & OD & D & $\%$ morb. & M & $\%$ mort \\
\hline Verão & 28,5 & 6,5 & 0,055 & 1,3 & 5,3 & 67,8 & 4,5 & 26 & 52,0 & 24 & 48,8 \\
Outono & 21,2 & 6,5 & 0,064 & 6,4 & 9,6 & 30,2 & 4,3 & 27 & 60,0 & 18 & 40,0 \\
Inverno & 22,6 & 6,8 & 0,120 & 2,6 & 19,0 & 49,0 & 5,3 & 20 & 36,4 & 35 & 63,6 \\
Primavera & 24,6 & 6,2 & 0,140 & 3,8 & 21,0 & 42,4 & 4,4 & 32 & 30,5 & 73 & 69,5 \\
\hline
\end{tabular}

$\%$ morb $=\%$ de morbilidade; $\mathrm{D}=$ Doentes; $\mathrm{M}=$ Mortos; $\%$ mort $=\%$ de mortalidade. 
Outro fator que pode ter favorecido a patogenicidade das E. tarda nas tilápias foi o acúmulo excessivo de matéria orgânica no viveiro (Noga, 1996) proporcionado pela consorciação com suínos (Perdomo, 1996), caracterizado pelas características físico-químicas da água do viveiro (Tab. 2).

A presença de Edwardsiella tarda nas tilápias é característica de animais de sangue frio (Pastor, 1981; Holt, et al., 1994; Noga, 1996; Nettles \& Sexton, 1997; Pavanelli et al., 1998), entretanto, em função do seu poder patogênico (Pastor, 1981; Doyle, 1989; Bernoth, 1991; Nettles \& Sexton, 1997; Pavanelli et al., 1998), a liberação desses peixes para alimentação humana deve ser bem avaliada pelas autoridades competentes.

Os peixes produzidos na fazenda onde foi realizado o experimento são fornecidos para pesque-pagues, produtores rurais em geral e consumidores diretos. Assim, essas tilápias podem ser consumidas cruas, representando grave risco sanitário para saúde do consumidor por pertencerem à classe de risco tipo 2 (Brasil, 1997).

\section{CONCLUSÕES}

Em tilápias criadas em viveiro com dejetos de suínos a mortalidade por septcemia dos peixes tropicais é maior no inverno e na primavera. $\mathrm{O}$ isolamento de Edwardsiella tarda mostra o potencial patogênico de transmissão do microrganismo na carne crua de peixes.

\section{REFERÊNCIAS BIBLIOGRÁFICAS}

BERNOTH, E.M. Risk assessment of bacterial infection from consumption of freshwater fish. Bundesgesundheitsblatt, v.34, p.6-8, 1991.

BRASIL. Instrução Normativa nº 7. Diário Oficial, República Federativa do Brasil, Brasília, p.11.827-11.833, 9 jun 1997. Seção 1, 1997b.

DOYLE, M.P. Foodborne bacterial pathogens. In: HOLT, J.G., KRIEG, N.R., SNEATH, P.H.A. et al. Bergey's manual of determinative bacteriology. 9.ed. Maryland: Williams \& Wilkins 1994.

NETTLES, R.E., SEXTON, D.J. Successful treatment of Edwardsiella tarda prosthetic valve endocarditis in a patient with AIDS. Clin. Infect. Dis., v.25, p.918-919; 1997.

NOGA, E.J. Fish disease. Missouri: Mosby, 1995. 367p.

PASTOR, E.Z. Principales enfermidades infecciosas de los peces. Barcelona: Aedos, 1981. 175p.

PAVANELLI, G.C., EIRAS, J.C., TAKEMOTO, R.M. Doenças de peixes: profilaxia, diagnósticos e tratamentos. Maringá: Nupleia, 1998. 264 p.

PERDOMO, C.C. Impacto da suinocultura sobre o meio ambiente. In: Conferência Internacional Sobre Ciência e Tecnologia de Produção e Industrialização de Suínos, 2, 1996, Campinas. Anais... Campinas, CTC-ITAL, 1996. p.87-97.

POST, G. Textbook of fish health. Hong Kong: T.F.P. Publications, 1983.

SINGH, B.R., SINGH, K.P. Virulence factors of Edwardsiella tarda isolated from fish. J. Food Sci. Technol., v.34, p.450-453, 1997.

WANG, W.S., WANG, D.H. Enhancement of resistance of tilapia and grass carp to experimental Aeromonas hydrophila and Edwardsiella tarda infections by several polysaccharides. Comp. Immunol. Microbiol. Infec. Dis., v.20, p.261-270, 1997. 